\title{
The Whole Process Research On Distribution Network Construction Projects Management Based On Information Management and Control
}

\author{
GUO Yuan ${ }^{1}$, YANG Chun-sheng ${ }^{1, *}$, HUA Chen-bing ${ }^{1}$, ZHANG Ji-fei ${ }^{1}$, GAO Wen-ju ${ }^{1}$, ZHANG Wei $^{1}$ \\ ${ }^{1}$ State Grid Linyi Power Supply Company, Linyi, 276003, Shandong
}

\begin{abstract}
Distribution network is an important public infrastructure for national economic and social development, bearing the people's growing expectation for better life. The new time urgently requires the construction of distribution network to be safer, better and more efficient. This paper relies on the team dream information system, Focusing on the safety, quality and schedule requirements of distribution network construction management, giving full play the supporting role of information system in engineering construction management, Creates closed-loop management of process nodes such as project preliminary design and feasibility study, materials, construction, completion, production, settlement and filing, so as to realize seamless connection of project preliminary design and feasibility study, efficient and transparent material management, deep integration of construction completion and close connection of production settlement, improve work efficiency and enhance the construction and management level of distribution network projects.
\end{abstract}

\section{Introduction}

Information is a historical process of making full use of information technology, developing and utilizing information resources, promoting information exchange and knowledge sharing, improving the quality of economic growth and promoting the transformation of economic and social development. In the $21 \mathrm{st}$, information and globalization are intertwined, which promotes the deepening of global industrial division of labor and the adjustment of economic structure. Information resources are increasingly becoming important factors of production, intangible assets and social wealth. Vigorously promoting the development of information, promoting industrialization with information and promoting information with industrialization have become important and urgent strategic tasks in the new stage of China's economic and social development (for example, [1]). Distribution network is one of the important infrastructures for modernization. It is the key which links connecting the main network, users and various distributed interactive terminals. It is also the key which provides high-quality electric energy for users. Its construction directly affects the development of urban economy and the improvement of people's living standard (for example, [2]). Basis on the previous research and practice, we build a system called team dream by using programming, establish an integrated module for the feasibility study of rural distribution network projects, a material module, a project plan management module and a settlement filing module to make sure project safety, quality and schedule to be under control, which effectively overcome the obvious shortage of distribution network planning support capacity, the early low participation of operation and maintenance units, low efficiency in the early stage of the project, the low project accuracy, the inaccurate construction and renovation plan, the changed design during the construction phase, the confusion between materials of rural distribution network project and other types of materials, the low efficiency of sending and receiving materials, The return of a large number of surplus materials affects the settlement of the project, poor rigid implementation of construction plan, personnel in place to supervise poor performance of duties, unclear project progress, inadequate management of construction personnel, low rate of obtaining evidence for concealed works supervision, untimely settlement and final accounts, have improved the application of information technology on distribution network construction projects, improved the resource allocation ability and intelligence level of distribution network, and satisfied the increasingly diverse power service needs of the people (for example, [3]).

\section{Build an integrated module for feasibility study and preliminary design}

Relying on the team dream information system, we establish the hidden danger database and requirement library of distribution network projects. The hidden 
danger library includes equipment potential safety hazards, overloads of distribution lines, secondary hidden dangers of equipment; The appendage units timely maintain the basic data according to the equipment conditions and classify according to the priority of hidden dangers; According to the classification of hidden danger database, the requirement library will give priority to the hidden danger (for example, [4]).

During the feasibility study and design stage of the project, based on the situations of the demand database projects, Jointly with territorial units to jointly carry out the feasibility study and design of the project, with the combination of distribution network demand database and project site survey, the planning scheme is further optimized in the process of site survey in combination with site conditions and some external factors, and the feasibility of the project is verified, and the Projects which can not be implemented are marked and explained in the system (for example, [5]). Adhere to the principle that preliminary work can only be carried out when the projects are included in the demand library, and form a planning feedback mechanism.

\section{Establish material module of distribution network project}

We establish the material module of the distribution network project, and the material incoming and outgoing ledgers are established one by one, in order to form a material management mode of "receiving goods by special personnel of the owner's project department-registering for warehousing-centralized storage in the warehouse of the local unit of the project-batch acceptance and delivery in ministry of materials and equipment-registering for outgoing". The material management department of the owner's project departments carry out material expediting with ministry of materials and equipment is responsible for jointly, and the material warehouse of the territorial unit of the project is responsible for receiving materials; The material management of the owner's project department is responsible for the inventory of materials in storage and the account record of the team dream to avoid confusions between materials of the distribution network project and other types of materials.

\section{Establish project plan management module}

Relying on the team dream, the distribution network project plan management module is established. According to the batch and the number of monomers (for example, [6]), each monomer project construction nodes should be controlled by the construction plan such as commencement, pole pit excavation, tower assembly, conductor erection, equipment installation and completion according to the construction process, and also on-site confirmation is included. Each construction project department collects the next day's construction plans in advance every day and submits them to the owner's project department for review, and then submits them to the team dream system. Each territorial supervision unit shall supervise in place according to the construction plan, and confirm the key nodes such as actual commencement and completion of the project one by one according to the actual construction situation every day. The owner's project department promptly urges backward construction units to speed up the construction of the project according to the operating rate and completion rate of each unit automatically calculated by the team dream system every week. Against the individual units with slow progress and many problems, we will concentrate on helping them, and make overall plans to solve difficulties such as insufficient construction force, slow arrival of materials and many civil problems, so as to ensure the overall advancement of cities and counties (for example, [7]).

\section{Establish settlement filing management module}

Relying on the team dream system we establish a project settlement filing module, make settlement tasks and time nodes look so clear, the design units will carry out as-built drawing after the completion of the single project, and complete the delivery of as-built drawings within 10 days after the completion and production of the large package project. The construction units shall complete the preparation of equipment and materials countersign form, quantity visa and project settlement book within 20 days after the project is completed and put into production, and submit it to the supervisor for review; The supervision units shall complete the audit within 7 days from the receiving the materials date submitted by the construction units, and issue the supervision settlement audit report; The owner's project department shall submit the project completion acceptance report(for example, [8]), as-built drawing, equipment and material countersign form, quantity visa, settlement book after supervision audit, supervision audit report and other materials to the audit department within 3 days, and entrust an external audit company to audit. The external audit company shall complete the settlement audit within 30 days (for example, [9]). After issuing the audit final statement, the project department of each owner shall notify the construction, design, supervision and auditing units to issue invoices and make service confirmation. The finance department shall complete the transfer of final accounts within 10 days after all invoices are recorded. Within the month that the project is completed and put into production, the operation and maintenance management units shall provide the owner's project department with the asset card of the completed project, upload the project completion acceptance report to the team dream system for review, and cooperate with the finance department to complete the completion and capital transfer (for example, [10]). After the completion of the single project, the construction party sorted out the list of equipment and materials actually used on the site on the same day, and uploaded it to the team dream after being reviewed and confirmed by the supervisor. After 
the completion acceptance of the project package, summarize the equipment and materials list, fill in the completion acceptance report and upload it to the team dream to ensure the consistent quantities (for example, [11]). The construction unit shall hand over the project filing data as the payment condition for the construction fee, and perform the prescribed examination and approval procedures. The signature must be manually signed by myself.

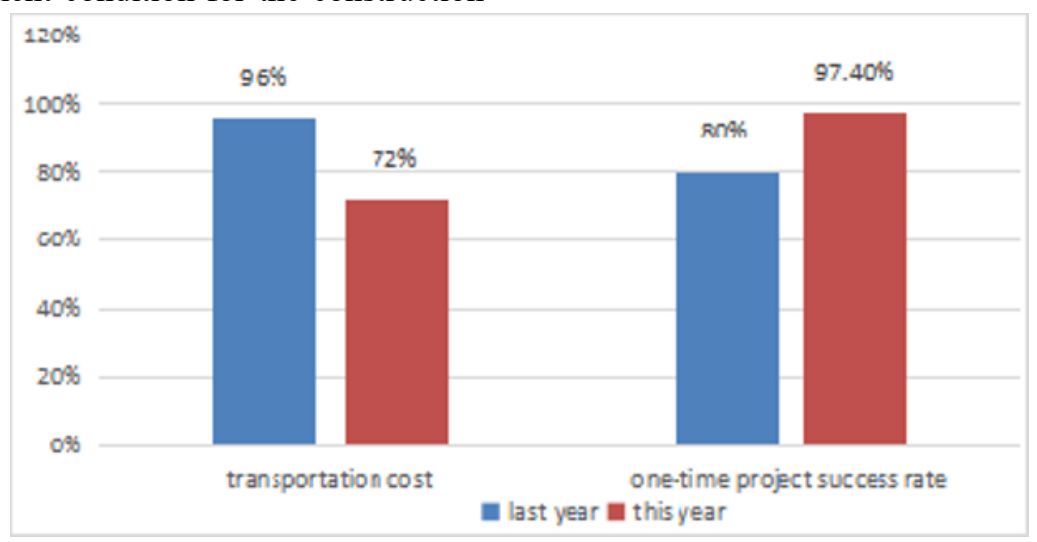

Figure 1 the desired effect

Table 1 the desired targets

\begin{tabular}{|c|c|c|}
\hline Number & Contents & Figures \\
\hline 1 & multiple power supply (billion $\mathrm{kWh}$ ) & 2.4 \\
\hline 2 & saving cost (yuan) & 160000 \\
\hline 3 & Benefits (yuan) & 1400000 \\
\hline 4 & production date (day) & 60 \\
\hline
\end{tabular}

\section{Summary}

Innovate the management means of rural distribution network construction project by using the team dream system, we establish an integrated module for the feasibility study of rural distribution network projects, a material module for distribution network projects, a project plan management module, a settlement filing module, etc., adopting the method of "overall control of large project packages and daily and weekly adjustment of single project", Dynamically track the construction and settlement progress of each unit, the construction plan shall be submitted daily, settlement progress is updated daily, automatically summarize to form weekly and monthly reports, reduce artificial evaluation factors, avoid repeated statistics by managers, reduced the burden on the grassroots, realize the refined closed-loop management of the whole process of "project requirements-material submission-process control-settlement filing", giving full play to the supporting role of information system in engineering construction management, which can strengthen the control of project safety, quality and schedule, help the construction of strong smart grid and the integrated development of urban and rural power grids, provide safer, more economical, clean and sustainable power supply, improve the construction and management level of distribution network projects, and achieve remarkable management, economic and social benefits ${ }^{[7]}$.

\section{References}

1. Taylor C W, Erickson D C,Martin K E, etal. WACS wide-area stability and voltage control system: R\&D and online demonstration [C].Proceedings of the IEEE, 2005, 5: 892-906 .

2.Yang Shi-rong. Research on wide-areaprotection based on wide-area measurement information of power grid [D]. Wuhan: Huazhong University of Science and technology, 2006.

3. Zhang Jing-jing, Ding Ming. Research on the wide-area protection system[J]. Journal of HEFEI University Of Technology (Natural Science). 2006, 29(4): 440-443.

4. Cong Wei, Pan Zhen-cun, Ding Lei, etal. Wide-area protection system to defend three different types of 
power system stability problems and its application[J]. Power System Technology, 2004, 28(18): 29-33.

5. Hu Xue-hao. Rethingking and enlightenment of large scope blackout in interconnected North America power grid [J]. Power System Technology, 2003, 27(9): 2-6

6. Begovic M, Novosel D, Karlsson D, etal. Wide area protection and emergency control [J]. Proceedings of the IEEE, 2005, 93 (5): 876- 891.

7. Cai Yun-qing, Wang Lei, Zhou Fengquan, etal. Current status and prospect of wide-area protection (dynamic stability control) technologies[J]. Power System Technology, 2004, 28 (8) :20-33.
8. Yi Jun, Zhou Xiao-xin. A survey on power system wide-area protection and control [J]. Power System Technology, 2006, 30(8): 7-12.

9. Xiao Jian, Wen Fu-shuan. Wide-area protection and its applications [J]. Proceedings of the CSU-EPSA, 2008, 20(2): 22-35.

10. Milosevic, Borka D, Begovie, Miroslav. Voltage stability protection and control using a wide area network of phasor measurements [J]. IEEE Trans on Power Systems, 2003, 18 (1): 121- 127.

11. Lin Xia, Gao Hou-lei. Study of a new type of wide-area backup protection scheme[J]. Relay, 2005, 33(7):84 88. 